Volume 2 Nomor 2, September 2020, Halaman 85 - 94.

\title{
Sosialisasi Keselamatan Berkendara (Safety Riding) pada Siswa TK Mutiara DWP Indramayu
}

\author{
Eko Maulana Syaputra' ${ }^{1)}$, Ade Rahmawati' ${ }^{2)}$, Tayong Siti Nurbaeti), \\ Riantina Luxiarti ${ }^{4}$ \\ ${ }^{1,2,3)}$ Program Studi Kesehatan Masyarakat Universitas Wiralodra \\ ${ }^{4)}$ Program Studi Perekam dan Informasi Kesehatan Stikes Mahardika Cirebon \\ Email : ekomaulanasyaputra@unwir.ac.id, aderahmawati@unwir.ac.id, \\ t.siti.nurbaeti@gmail.com, riantina@stikesmahardika.ac.id
}

\begin{abstract}
Abstrak
Data Polres Indramayu menyebutkan tahun 2018 terdapat kasus kecelakaan lalu lintas sebesar 107.968 kasus. Dimana terdapat korban meninggal dunia sebesar 29.083. Serta terdapat 16\% (2.546) usia 0-4 tahun menjadi korban kecelakaan lalu lintas. Masih rendahnya tingkat pengetahuan dan kesadaran orang tua dalam menerapkan keselamatan berkendara menjadi salah satu penyebab tingginya kecelakaan lalu lintas tersebut. Salah satu penyebabnya adalah ketika orang tua mengantarkan maupun menjemput anaknya ke sekolah tidak menggunakan helm pada anaknya maupun perlengkapan keselamatan berkendara lainnya. Pengabdian kepada masyarakat ini bertujuan untuk mensosialisasikan pentingnya safety riding (keselamatan berkendara) pada siswa TK Mutiara DWP Indramayu. Dari hasil penyuluhan yang telah dilakukan, diperoleh hasil bahwa terdapat peningkatan pengetahuan terkait keselamatan berkendara dimana diperoleh hasil pretest $72,3 \%$ meningkat menjadi $87,2 \%$ pada saat dilakukan post test. Sosialisasi yang diberikan yaitu berupa praktik penggunaan helm yang benar, memilih dan mewarnai gambar serta menyanyikan lagu safety riding. Analisis data menggunakan deskriptif kuantitatif. Diperlukan adanya pengabdian lanjutan, khususnya mengenai safety riding bagi orang tua terutama untuk ibu-ibu. Perlu adanya kesadaran dari pihak orang tua tentang pentingnya safety riding untuk anak, khususnya kewajiban pemakaian helm. Pihak sekolah sebaiknya melakukan pengawasan dan memberikan materi khusus mengenai pentingnya safety riding bagi siswa TK.
\end{abstract}

Kata kunci: safety riding, Siswa TK, Pengetahuan

\begin{abstract}
Indramayu police data showed 2018 that 107,968 cases of traffic accidents occurred. Where the death toll stands at 29,083. And there were $16 \%(2,546) 0-4$ years of age who were victims of a traffic accident. Still a poor level of parental knowledge and awareness in applying safety drives was one of the causes of the
\end{abstract}


high traffic accidents. One of factor was when the parents drop off and take their children to school without helmets on them or other driving safety equipment. This devotion to the community was intended to socialize the importance of safety riding on the kindergarteners. Based on the training, it was obtained that there was an increased knowledge of safety on the drive where pretest of $72.3 \%$ increased to $87.2 \%$ at the time of the post test. Socializing has been the practice of using proper helmets, selecting and coloring pictures and singing safety riding songs. Data analysis used quantitative descriptive. Further devotion is required, especially regarding safety riding for parents primarily for mothers. Parental awareness of the importance of safety riding to the child, especially the wearing of the helmet. The school should do surveillance and provide special materials regarding the importance of safety riding to kindergarten students.

Key word: safety riding, Kindergarten students, knowledge

\section{A. Pendahuluan}

Pada tahun 2106, angka kejadian kecelakaan lalu lintas di Provinsi Jawa Barat, cukup tinggi yaitu sebesar 6861 kejadian kasus (BPS, 2016). Kemudian Pada tahun 2018 di Kabupaten Indramyu terdapat kasus kecelakaan lalu lintas yang cukup tinggi juga yaitu sebesar 107968 kasus, diantaranya sebanyak 29.083 korban dinyatakan meninggal dunia. Prevalensi kejadian kasus kecelakaan lalu lintas pada anak usia 0-4 tahun sebesar 16\% (2.546). Data ini mengindikasikan bahwa masih cukup tinggi kejadian kecelakaan lalu lintas pada anak, dimana kejadian kecelakaan tersebut berasal dari sebagian besar pengendara sepeda motor. Hal ini, mengindikasikan masih tingginya kecelakaan lalu lintas khususnya pada anak di Kabupaten Indramayu.

Safety riding adalah perilaku mengemudi yang aman dan sesuai aturan yang dapat melindungi pengendara dari terjadinya kecelakaan lalu lintas. Safety riding di rancang untuk meningkatkan awareness (kesadaran) pengendara terhadap segala potensi bahaya selama berkendara sehingga tercipta perilaku aman dalam berkendara. Safety riding selain memperhatikan keselamatan pengemudi juga memperahatika. keselamatan penumpang (Dinas Perhubungan RI, 2005). Perlengkapan safety riding yang digunakan seperti helm, masker, sepatu, sarung tangan, serta pakaian atau jaket pelindung (UU No. 22 tahun 2009).

Menurut Smet (1994), menjelaskan bahwa keluarga merupakan tempat pertumbuhan dan perkembangan individu. Selain itu keluarga merupakan tumpuan harapan, tempat bercerita dan mengeluarkan keluhan-keluhan bila individu mengalami persoalan. Peran orang tua bertujuan untuk meningkatkan kesadaran dan sebagai upaya mengajarkan perilaku yang aman dalam berkendara. Pada dasarnya, secara alami anak akan mengikuti sifat dan perilaku orang tua. Anak akan meniru setiap perilaku yang dilakukan orang tua. Perilaku orang tua yang memtuhi aturan dalam berkendara secara tidak langsung dikemudian hari anak juga akan 
meniru perilaku tersebut, begitu juga sebaliknya. (Muir, 2010). Dari sosialisasi ini diharapkan tumbuhnya kesadaran dan dukungan yang diberikan oleh keluarga khususnya orang tua kepada anaknya agar selalu menerapkan safety riding dalam berkendara.

Penggunaan sepeda motor mengalami perkembangan yang cepat pada Negara-negara berkembang di wilayah Asia. Indonesia termasuk Negara yang penggunaan sepeda motornya cukup tinggi, Sepeda motor merupakan moda transportasi bagi kebanyakan masyarakat di Indonesia dan beberapa negara lain seperti Malaysia (Sivasankar et al, 2013). Di Indonesia sudah umum terlihat bahwa anak-anak akan berboncengan dengan orang dewasa yang mengendarai sepeda motor. Penerapan safety riding akan bermanfaat bagi keselamatan berkendara. Hal ini juga berlaku bagi pengendara tetapi juga bagi orang yang membonceng. Keselamatan ketika membonceng perlu menjadi perhatian selain pada orang dewasa, keselamatan pada anak-anak juga sangat penting diutamakan. Hal ini perlu mendapat perhatian karena keselamatan berkendara adalah salah satu cara dalam mengurangi risiko cedera jika terjadi kecelakaan.

Penelitian mengenai penggunaan helm di antaranya di laporkan oleh Liu et al, (2003) dengan hasil penelitian bahwa helm memberi manfaat perlindungan dengan mengurangi risiko cidera seperti cidera leher. Intervensi edukasi penggunaan helm akan berdampak pada tingkat morbiditas dan mortalitas akibat kecelakaan berkendara. Program edukasi mengenai penggunaan helm perlu di dukung oleh legalitas seperti adanya undang-undang. Carr et al (1995) melaporkan di Australia pengaruh kampanye penggunaan helm yang di dukung dengan penerapan undang-undang berpengaruh pada peningkatan pemakaian helm yang signifikan. Menurut Goniewicz et al (2017) dan Liu et al (2016) terjadinya kasus kecelakaan pada anak dibawah usia 7 tahun disebabkan karena masih lemahnya pengawasan dan kepedulian orang tua tentang pentingnya safety riding.

Berdasarkan hasil observasi oleh penulis mengenai faktor potensial yang dapat mengakibatkan kecelakaan lalu lintas di jalan raya pada siswa sekolah TK tersebut diantaranya adalah: (1) Lokasi sekolah TK Mutiara DWP berada di jalan raya yang dilalui kendaraan seperti elf atau mini bus, angkot, sepeda motor, mobil dan sebagainya, sehingga berpotensi tinggi untuk terjadinya kecelakaan lalu lintas. (2) sebagian besar orang tua ketika mengantarkan dan menjemput anaknya kesekolah tidak menggunakan helm dan perlengkapan safety riding lainnya (3) sebagian orang tua menganggap hanya orang dewasa yang wajib menggunakan helm sedangkan untuk anak kecil tidak perlu menggunakan helm (4) belum terdapatnya materi khusus apalagi kurikulum di sekolah mengenai pentingnya safety riding pada anak. Berdasarkan latar belakang tersebut, maka penulis ingin melakukan pengabdian mengenai sosialisasi keselamatan berkendara (safety riding) bagi siswa TK Mutiara DWP Indramayu dengan tujuan agar siswa TK tersebut dapat mengingatkan orang tua tentang pentingnya safety riding serta dapat menjadi agent of change dan pelopor keselamatan dalam berkendara. Selain itu, 


\section{ABDI WIRALODRA}

JURNAL PENGABDIAN KEPADA MASYARAKAT
ISSN 2656-5501 (Print)

ISSN 2714-8041 (Online)

intervensi edukasi mengenai safety riding ini diharapkan dapat merubah pengetahuan, sikap dan juga perilaku dalam berkendara. Hal ini juga diharapkan akan memberi dampak positif dalam jangka panjang dalam perilaku berkendara.

\section{B. Metode}

Metode yang digunakan dalam analisis data menggunakan deskriptif kuantitatif. Waktu Pelaksanaan dilakukan pada Bulan April-Agustus 2019. Sosialisasi keselamatan berkendara (safety riding) ini dilaksanakan di TK Mutiara DWP Indramayu. Sasaran kegiatan ini adalah anak-anak TK Mutiara DWP kelas B. Diharapkan setelah mengikuti sosialisasi safety riding ini anak-anak TK tersebut dapat menjadi pelopor keselamatan berkendara dan dapat menjadi agent of change khususnya dapat mengingatkan kepada kedua orang tua mereka tentang pentingnya menerapkan safety riding ketika berkendara termasuk mengantarkan anak ke sekolah. Berikut ini merupakan tahapan pelaksanaan pengabdian kepada masyarakat tersebut :

a) Persiapan : melakukan koordinasi dengan mitra, melakukan perijinan, melakukan briefing kepada guru TK yang akan membantu dalam kegiatan pengabdian, pembuatan kuesioner, dan instrumen penelitian berupa lagu safety riding.

b) Pelaksanaan : Pretest, melakukan edukasi dan praktik pemakaian helm, bernyanyi lagu safety riding dan praktik pemakaian helm dan melakukan postest.

c) Evaluasi dan tindak lanjut : melakukan monitoring selama 3 bulan untuk melihat ada perubahan pada responden.

\section{Hasil Pengabdian dan Pembahasan}

1) Hasil Pengabdian

a. Tahap Kegiatan

1. Tahap Persiapan

a. Pengurusan ijin dan administrasi

b. Persiapan pembuatan kuesioner dan instrumen (berupa pembuatan lagu safety riding)

2. Tahap Pelaksanaan :

a. Persiapan : briefing dengan guru TK yang membantu dalam pengabdian, persiapan alat dan bahan pengabdian

b. Pelaksanaan : Pre test, sosialisasi safety riding, praktik penggunaan helm dengan baik dan benar, menyanyikan lagu safety riding yang sebelumnya sudah dihapalkan dengan guru TK yang membantu, dan melakukan post test. 


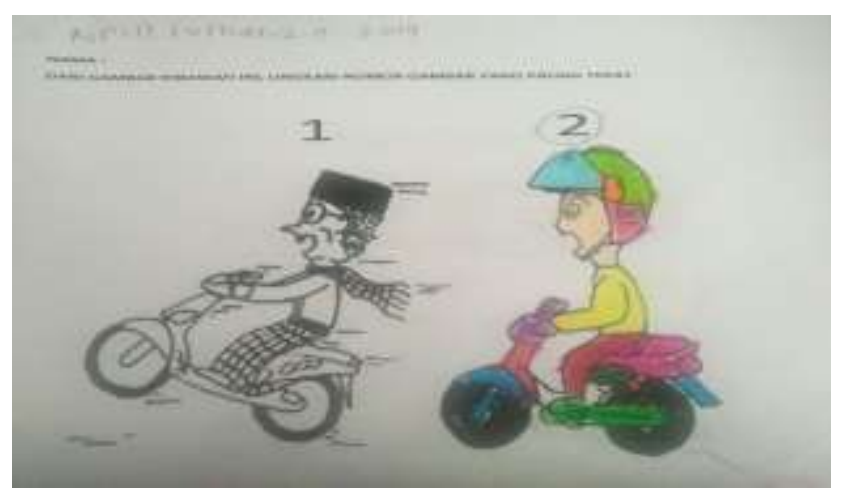

Gambar 1. Memilih gambar safety riding yang benar dengan cara diwarnai

Intervensi yang diberikan yaitu berupa siswa TK diminta memilih dan mewarnai beberapa gambar yang benar. Intervensi bertujuan untuk mengetahui tingkat pengetahuan para siswa TK mengenai safety riding. Gambar safety riding yang ditanyakan yaitu mengenai tidak kebut-kebutan di jalan raya, tidak menggunakan handphone ketika berkendara, tidak menerobos lampu merah dan sebagainya. Dari hasil tersebut sebagian besar para siswa dapat memilih serta mewarnai gambar safety riding dengan baik dan benar.

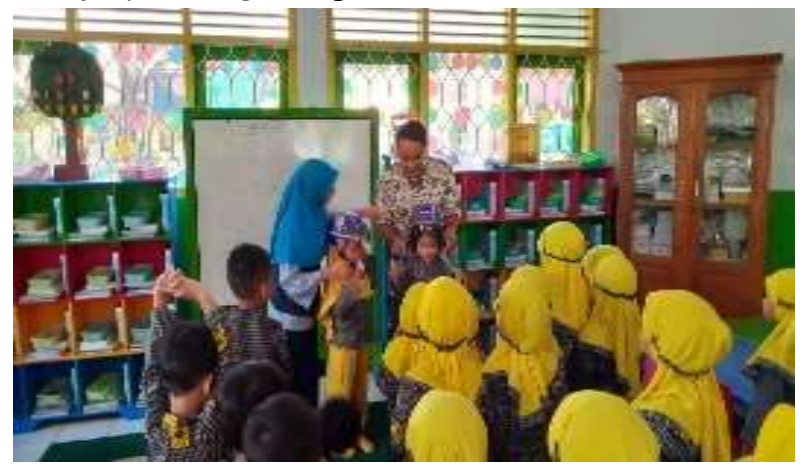

Gambar 2. Menyanyikan lagu safety riding dan praktik pemakaian helm yang benar

Sosialisasi berikutnya yang diberikan yaitu berupa menyanyikan lagu dibantu guru tentang safety riding. Para siswa TK diminta menyanyikan lagu safety riding yang telah diberikan beberapa hari sebelumnya dan para siswa diminta untuk menghapal lagu safety riding tersebut. Selain sosialisasi dengan cara menyanyikan lagu safety riding para siswa juga diberikan praktik tentang cara pemakian helm dengan baik dan benar sampai bunyi "klik". Pemberian sosialisasi berupa pemakaian helm dan menyanyikan lagu safety riding tersebut diharapkan timbulnya perilaku mengenai pentingnya penerapan safety riding ketika berkendara. 


$\begin{array}{ll}\text { ABDI WIRALODRA } & \text { ISSN 2656-5501 (Print) } \\ \text { JURNAL PENGABDIAN KEPADA MASYARAKAT } & \text { ISSN 2714-8041 (Online) }\end{array}$

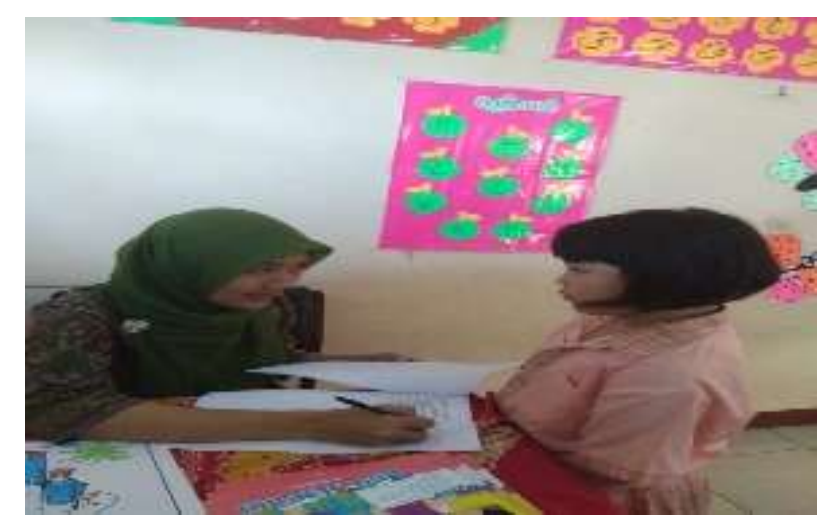

Gambar 3. Wawancara dengan responden dibantu guru TK

Setelah diberikan intervensi berupa memilih dan mewarnai gambar safety riding, menyanyikan lagu safety riding serta praktik pemakaian helm dengan baik dan benar selanjutnya yaitu monitoring dan evaluasi. Monitoring yang dilakukan yaitu berupa meminta bantuan para guru untuk memantau setiap hari anak yang datang dan dijemput dari sekolah yang menggunakan helm. Monitoring ini menggunakan checklist. Selain itu, penulis juga dibantu guru TK tersebut mengambil data responden dengan cara wawancara terkait safety riding yang telah diberikan. Setelah itu, penulis melakukan evaluasi terhadap hasil wawancara kemudian dianalis seberapa manfaat dan apakah terjadi peningkatan pengetahuan pada siswa TK yang telah diberikan sosialisasi.

Tujuan dari pengukuran pretest dan postest adalah untuk mengetahui pengetahuan anak TK sebelum dan sesudah diberikan intervensi edukasi berupa sosialisasi keselamatan berkendara. Jumlah peserta dalam sosialisasi ini yaitu sebanyak 47 anak TK Mutiara DWP di kelas B. kelas B dipilih karena anak sudah lebih besar dan cukup umur daripada yang kelas A dan kelas PAUD. Sosialisasi yang dilakukan yaitu berupa praktik pemakaian helm dengan baik dan benar, menyanyikan lagu safety riding dan memilih gambar yang benar kemudian diwarnai gambar safety riding tersebut. Berikut ini merupakan hasil pretest dan postest pengetahuan safety riding yang tersaji dalam tabel 1 berikut:

$\begin{aligned} & \text { Tabel 1. distribusi frekuensi pretest dan post test pengetahuan te } \\
& \text { Safety riding }\end{aligned}$
\begin{tabular}{lll}
\hline Pengetahuan & $\mathrm{F}$ & $\%$ \\
\hline Pretest & & \\
Baik & 34 & 72.3 \\
Tidak Baik & 13 & 27.7 \\
Jumlah & 47 & 100 \\
\hline Postest & & \\
Baik & 41 & 87,2 \\
Tidak baik & 6 & 12,8 \\
Jumlah & 47 & 100 \\
\hline
\end{tabular}


Berdasarkan Tabel 1 diperoleh hasil bahwa sebagian besar nilai pretest pada responden tentang safety riding kategori baik sebesar 72,3\% sedangkan pada saat pemberian postest terdapat peningkatan pengetahuan tentang safety riding sebesar 87,2\%. Pengkategorian variabel menggunakan cut off point median dikarenakan data berdistribusi tidak normal dengan nilai sebesar 7,3. Dikategorikan baik jika $\geq$ 7,3, sedangkan kategori tidak baik $<7,3$.

\section{2) Pembahasan}

Intervensi edukasi yang diberikan kepada siswa berupa sosialisasi safety riding (keselamatan berkendara) diperoleh hasil yaitu terdapat peningkatan pengetahuan setelah sosialisasi diberikan sebesar 87,2\%. Setelah sosialisasi diberikan, kami memberikan partisipan kuesioner sebagai evaluasi terhadap sosialisasi yang sudah diberikan.

Dari hasil pengabdian yang dilakukan kemudian penulis melakukan monitoring selama 3 bulan diperoleh hasil bahwa para siswa TK dapat memilih dan mewarnai dengan baik gambar safety riding. Lagu safety riding juga dapat dinyanyikan dan dihapal dengan baik serta siswa TK mulai menggunakan helm ketika akan berangkat sekolah. Para siswa TK tersebut mulai merespon dengan cara meminta kepada kedua orang tuanya untuk dibelikan helm dan untuk bisa dipakai ketika ke sekolah maupun bepergian dengan kendaaran bermotor. Hal ini sebagai salah satu indikator keberhasilan sosialisasi yang telah dilakukan. Dimana harapan penulis dengan diadakannya sosialisasi safety riding ini para siswa TK tersebut dapat mengingatkan orang tua untuk menggunakan helm pada siswa. Selain itu siswa juga dapat sebagai agent of change sebagai pelopor keselamatan dalam berkendara.

Sebelum diberikan sosialisasi dan intervensi mengenai safety riding sebagian besar para siswa TK sebagaian besar para siswa TK ketika diantar maupun dijemput kesekolah tidak dipakaikan helm oleh orang tuanya. Setelah diberikan sosialisasi para siswa sudah mulai diberikan helm oleh orang tuanya karena adanya pengawasan yang lakukan penulis dibantu guru pendamping.

Peningkatan pada pengetahuan akan berpengaruh terhadap sikap dan perilaku berkendaraan yang sesuai dengan aturan keselamatan. Peningkatan keselamatan berkendara melalui edukasi merupakan salah satu pilar dalam WHO mengenai keselamatan berkendara (WH0, 2010). Pengetahuan seseorang tentang pencegahan kecelakaan lalu lintas dapat menjadi salah satu faktor penentu terjadinya insiden di jalan raya. Semakin tinggi pengetahuan pengendara mengenai aturan dan rambu-rambu lalu lintas dapat menurunkan potensi bahaya mengalami kecelakaan lalu lintas. Sikap dan perilaku dipengaruhi oleh pengetahuan yang mereka ketahui. (Ward, 1997).

Penggunaan helm merupakan salah satu aspek penting dalam keselamatan berkendara. Permasalahan masih rendahnya penggunaan helm pada pengendara 
juga di laporkan di beberapa negara seperti Malaysia, Vietnam, India. (Azhar et al, 2010; Ichikawa et al 2013; Swaroop et al 2014). Padahal, kewajiban penggunaan helm juga tertuang dalam peraturan perundang-undangan. Penggunaan helm akan mengurangi risiko dan parahnya cedera kepala akibat kecelakaan lalu lintas. Sehingga sosialisasi penggunaan helm pada anak-anak merupakan salah satu cara dalam mempromosikan keselamatan bekendara. Menurut Watson et al (2007), dengan memberi informasi dan edukasi berupa pentingnya keselamatan berkendara pada pengendara dapat meningkatkan pemahaman dan pengetahuan tentang tata cara berkendara yang aman dan selamat bagi pengendara di Australia.

Heily (2003) menyebutkan bahwa dengan memberikan pembelajaran tentang safety riding kepada anak TK berupa cara menggunakan atau mengendarai transportasi umum, memberikan edukasi berupa rambu-rambu lalu lintas membuat anak TK di Washington mengetahui tentang berkendara yang aman. Penerapan perlengkapan untuk keselamatan berkendara juga akan berdampak pada pengurangan risiko kematian dan cedera akibat kecelakaan lalu lintas. Pengetahuan sikap dan perilaku orang tua terhadap keselamatan berkendara juga faktor penting dalam penerapan safety riding pada anak-anak (Raman et al, 2012).

Program pendidikan keselamatan lalu lintas sangat diperlukan untuk memberikan edukasi dan kesadaran tentag pentingnya keselamatan berkendara khususnya pada anak. Dengan diajarkannya dasar keselamatan lalu lintas di sekolah, anak-anak dipersiapkan untuk membangun pengetahuan tentang lalu lintas, dan sikap positif yang akan mendatangkan manfaat saat anak-anak itu menjadi dewasa di masa yang akan datang. Memberikan edukasi dan pemahaman serta kebiasaan baik di usia dini lebih mudah daripada menghilangkan kebiasaan buruk ketika sudah dewasa. Materi-materi dasar lalu lintas untuk anak usia dini sebaiknya dikemas semenarik mungkin untuk menarik minat para siswa tersebut. Materi edukasi dapat berupa permainan, bermain peran, video edukasi dan lain sebagainya (Nopani, 2012).

\section{Kesimpulan dan Saran \\ Kesimpulan}

Kegiatan sosialisasi keselamatan berkendara (Safety Riding for Kids) pada Siswa TK Mutiara DWP Indramayu telah dilaksanakan dan terdapat peningkatan pengetahuan responden dimana pada pretest sebesar $72,3 \%$ meningkat sebesar $87,2 \%$ pada saat dilakukan postest. Dengan diadakannya sosialisasi safety riding ini para siswa TK tersebut dapat mengingatkan orang tua untuk menggunakan helm pada siswa dan harapannya yaitu para siswa juga dapat sebagai agent of change sebagai pelopor keselamatan dalam berkendara.

\section{Saran}

a. Perlu dilakukannya pengabdian lanjutan, khususnya mengenai safety riding bagi orang tua terutama untuk ibu-ibu. Karena sebagian besar yang mengantarkan anak ke sekolah adalah ibu. 
b. Perlu adanya pengawasan yang dilakukan oleh pihak sekolah berkolaborasi dengan orang tua agar anak diwajibkan selalu menggunakan helm ke sekolah

c. Perlu adanya materi pembelajaran tambahan mengenai pentingnya safety riding, karena hal tersebut perlu ditanamkan sejak dini kepada anak.

\section{Daftar Pustaka}

Azhar H, Yahaya A, and Wong SV. Child Helmet Efficacy for MotorcycleUse in Malaysia, MRev 04/2009. Kuala Lumpur: Malaysian Institute of Road Safety Research; 2010

Badan Pusat Statistik Provinsi Jawa Barat. Jumlah Kecelakaan Lalu Lintas Menurut Polres dan Kendaraan yang Terlibat di Provinsi Jawa Barat. Bandung. 2016.

Carr D, Skalova M, Cameron M. Evaluation of the bicycle helmet wearing law in Victoria during its first four years. Monash University Accident Research Centre 1995:No 76.

Dinas Perhubungan RI. Data Direktorat Jenderal Perhubungan Darat Direktorat Lalu Lintas dan Angkatan Jalan Subdit Keselamatan LLAJ. Jakarta. 2005.

Goniewicz, K, Goniewich, M., Pawlowski, W., Fiedor, P. 2017. Children Road Traffic Injuries in Poland, Journal of Pol J Public Health 2017;127(1): 4448. 2017.

Heily, T. Transportation Safety Education Curriculum for Preschool Children. Enterprise for Progress in the Community (EPIC). Washington. USA. 2003.

Ichikawa, M, Nakahara S, Phommachanh s, Mayxay M and Kimura A. Roadside observation of secondary school students' commuting to school in Vientiane, Laos. International Journal of Injury Control and Safety Promotion. Taylor \& Francis. http://www.tandfonline.com/loi/nics20. 2013. Liu, X., Yang, J., Chen X., Li, L. 2015. Knowledge, Attitudes and Behaviors on Child Passenger Safety among Expectant Mothers and Parents of Newborns: A Qualitative and Quantitative Approach. Journal of Pone, January 6. 2016.

Liu B, Ivers R, Norton R, Blows S, Lo SK. Helmets for preventing injury in motorcycle riders (Review). Published by John Wiley \& Sons, Ltd. doi: 10.1002/14651858.CD004333.pub2.2003.

Muir, C. (2010). Parents as Role Model in Road Safety. Monash University Nopani, D, Lestari, D, D dan Sumiaji, A., Pendekatan Pembelajaran Kooperatif Tip Role Playing Sebagai Upaya Peningkatan Pengetahuan Tentang Keselamatan Lalu Lintas Pada Anak Usia Dini, Jurnal PELITA, Volume VIII, Nomor 2, Agustus 2012. UNY, Yogyakarta. 2012.

Pamungkas, N,S. 2014. Mengenal Perilaku Pengendara Kendaraan dalam Upaya Mencegah Terjadinya Kecelakaan di Jalan Raya. Teknis. Vol.9, No.1. hal. 13-18.

Polres Indramayu. Data Kecelakaan Lalu Lintas. Indramayu. 2019. 
Raman, A, B , Michel D. Landry , C. Andrea Ottensmeyer, Susan Jacob, Elham Hamdan \& Manal Bouhaimed. Keeping our children safe in motor vehicles: knowledge, attitudes and practice among parents in Kuwait regarding child car safety. International Journal of Injury Control and Safety Promotion. 10.1080/17457300.2012.745578. 2012.

Sivasankarac, S K. Karmegama, M. T. Shamsul Bahria, H. Sadeghi Naeiniad \& S. Kulanthayan. 2014. Safety System for Child Pillion Riders of UnderboneMotorcycles in Malaysia. Publisher: Taylor \& Francis. http://dx.doi.org/10.1080/15389588.2013.861596

Smet, B. Psikologi Kesehatan. Jakarta: PT. Grasindo. 1994.

Suripno. Pertumbuhan Kendaraan Bermotor. 2007

Swaroop M, Siddique S M, Sagar S, Crandall M L. The problem of the pillion rider: India's helmet law and New Delhi's exemption. Elsevier. 2014.

Undang-undang Republik Indonesia nomor 22 tahun 2009. Tentang Lalu Lintas dan Permasalahannya. Jakarta.

Watson, B., Tunnicliff, D., White, K.,Schonfeld, C., Wishart, D., Psychological and Social Factors Influencing Motorcycle Rider Intentions and Behaviour. Document Retrieval Information. Quensland University of Technology, Australia. 2007.

Ward, H. Should injury prevention programmes be targeted? Injury Prevention 3, 160-162. 1997.

World Health Organization. Recommendations of the Expert Groupon Preventing Motorcycle Injuries in Children, Bangkok, Thailand.New Delhi, India:

WHO Regional Office for South-East Asia. 2010.

WHO. Global Status Report on Road Safety, WHO Library. 2015. 